\title{
Association between Serum Magnesium and Erythropoietin Responsiveness in Hemodialysis Patients: A Cross-Sectional Study
}

\author{
Ling Yu Jinghong Song Xiangxue Lu Yuan Zu Han Li Shixiang Wang \\ Department of Blood Purification, Beijing Chao-Yang Hospital, Capital Medical University, \\ Beijing, China
}

\section{Keywords}

Hemodialysis · Serum magnesium · Erythropoietin responsiveness · Erythropoietin resistance index $\cdot$ Related factor

\begin{abstract}
Background/Aims: As shown in the China Health and Nutrition Survey, serum magnesium is associated with anemia. However, the roles of magnesium in anemia and erythropoietin (EPO) responsiveness remain unclear in maintenance hemodialysis (MHD) patients. This study aims to investigate the level of serum magnesium and its relationship with EPO responsiveness in MHD patients. Methods: A total of 307 MHD patients were recruited for this survey. Laboratory data and anthropometrics were collected. EPO responsiveness was evaluated by the erythropoietin resistance index (ERI). The subjects were divided into 3 groups according to serum magnesium concentrations (group $A$, the lowest tertile; group $B$, the middle tertiles; and group $C$, the highest tertile). Multivariate logistic regressions were conducted to evaluate the factors that may be associated with EPO responsiveness. Results: The mean serum magnesium level was significantly higher than normal levels in MHD patients, while no hypomagnesemia was observed. A multivariate logistic regression model revealed that high-sensitivity C-reactive protein, intact parathyroid hormone, serum albumin, and magnesium levels were correlated with a high ERI. The OR of a high ERI was found to be 2.57 (95\% Cl 1.330-4.975, $p=0.005)$ for group A and $1.66(95 \% \mathrm{Cl} 0.878--3.140, p>0.05)$ for group B compared with the OR for group C. Conclusion: Serum magnesium levels were higher than normal levels in MHD patients. A high serum magnesium level was correlated with good EPO responsiveness and was therefore suggested to be a protective factor for EPO hyporesponsiveness.
\end{abstract}

L.Y. and J.S. contributed equally to this work. 


\section{Kidney \\ Blood Pressure \\ Research}

\begin{tabular}{l|l}
\hline Kidney Blood Press Res 2019:44:354-361 \\
\hline DOI: 10.1159/000500921 & $\begin{array}{l}\text { @ 2019 The Author(s). Published by S. Karger AG, Basel } \\
\text { www.karger.com/kbr }\end{array}$ \\
\hline
\end{tabular}

Yu et al.: Association between Serum Magnesium and EPO Responsiveness in Hemodialysis Patients: A Cross-Sectional Study

\section{Introduction}

Anemia is one of the most common complications that might seriously affect the quality of life in maintenance hemodialysis (MHD) patients. Anemia can increase the risk of complications of hypotension, heart failure, hospitalization rate, and mortality. The major cause of anemia is insufficient erythropoietin (EPO) levels in MHD patients. Unfortunately, a considerable proportion of end-stage renal disease patients exhibit a suboptimal hematologic response to EPO, as evidenced by the persistence of anemia despite adequate dosing or by the need for high-dose EPO therapy to achieve the recommended hemoglobin target. The definition of EPO hyporesponsiveness has been introduced to identify the inability to achieve or maintain target hemoglobin levels despite higher than usual doses of EPO. However, observational studies suggested that higher EPO doses were needed to achieve anemia correction associated with higher risks of all-cause mortality and cardiovascular events [1-4]. Several risk factors for EPO hyporesponsiveness have been identified, including inadequate iron administration, inflammation, malnutrition, suboptimal dialysis, secondary hyperparathyroidism, and malignancy [5].

Recent studies suggested that serum magnesium was associated with C-reactive protein [6], intact parathyroid hormone (iPTH) [7], and hemoglobin [6, 8] in MHD patients. However, the evidence to support the relationship between serum magnesium and EPO responsiveness is limited. Our study aims to investigate the serum magnesium level and its relationship with EPO responsiveness in MHD patients.

\section{Materials and Methods}

\section{Participants}

This study included all patients on MHD from December 2015 to March 2016 at the Department of Blood Purification, Beijing Chao-Yang Hospital, Capital Medical University. The inclusion criteria were as follows: (1) age > 18 years; (2) duration of dialysis > 3 months, in stable condition; and (3) use of arteriovenous fistula patients and volunteers to participate in this study. The exclusion criteria were as follows: (1) serious cardiacerebrovascular disease; (2) infectious diseases in nearly a month; (3) active liver diseases or advanced cancer; (4) recent blood transfusions or surgical procedures; (5) active bleeding or pure red cell aplasia; (6) nonuse EPO and (7) receiving phosphate chelators containing magnesium or laxatives containing magnesium.

All enrolled patients underwent hemodialysis 3 times per week and $4 \mathrm{~h}$ per dialysis. All patients were administered heparin anticoagulants and standard carbonate dialysis fluids; the dialysate flow was $500 \mathrm{~mL} /$ $\mathrm{min}$, and the blood flow rate was $200-350 \mathrm{~mL} / \mathrm{min}$. The dialysis liquid ingredients were as follows: sodium 138-140 mmol/L, potassium 2.0-2.5 mmol/L, calcium 1.25-1.5 mmol/L, and magnesium 0.5 mmol/L. All patients had KT/V >1.3.

The study was performed conforming with the declaration of Helsinki and approved by the Ethics Committee of Beijing Chao-Yang Hospital, Capital Medical University. The written informed consent was obtained from each participant.

\section{Data Collection}

The recorded demographic data of the patients included sex, age, weight, dialysis vintage, primary kidney disease, EPO, and iron treatments. All laboratory values (the average observation period) included routine blood tests, blood biochemistry, serum iron, total iron binding capacity, serum ferritin, iPTH, and high-sensitivity C-reactive protein (Hs-CRP), which were measured by automated and standardized methods before hemodialysis. Blood samples were collected after overnight fasting. Serum magnesium was measured by the colorimetric method (Siemens medical diagnostic products Co., Ltd., Shanghai, China) and whose normal level was from 0.75 to $1.02 \mathrm{mmol} / \mathrm{L}$.

All patients underwent recombinant human EPO injection (Yibiao, 4000 ${ }^{\mathrm{u}}$, Shenyang Sunshine Pharmaceutical Co., LTD., China). The EPO responsiveness was evaluated by the erythropoietin resistance index 


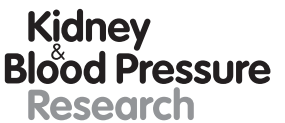

\begin{tabular}{l|l}
\hline Kidney Blood Press Res 2019;44:354-361 \\
\hline DOI: 10.1159/000500921 & $\begin{array}{l}\text { c } 2019 \text { The Author(s). Published by S. Karger AG, Basel } \\
\text { www.karger.com/kbr }\end{array}$ \\
\hline Yu et al.: Association between Serum Magnesium and EPO Responsiveness in
\end{tabular}

Yu et al.: Association between Serum Magnesium and EPO Responsiveness in Hemodialysis Patients: A Cross-Sectional Study

(ERI). The ERI was calculated by dividing the weekly weight-adjusted (kg) dose of EPO (IU) by the hemoglobin level $(\mathrm{g} / \mathrm{dL})$. When the serum albumin level was $<4.0 \mathrm{~g} / \mathrm{dL}$, the serum calcium level was adjusted as follows: corrected serum calcium level $(\mathrm{mmol} / \mathrm{L})=$ measured serum calcium level $(\mathrm{mmol} / \mathrm{L})+(40-$ serum albumin level $[\mathrm{g} / \mathrm{L}]) \times 0.02 \mathrm{mmol} / \mathrm{L}$. Transferrin saturation $(\%)=$ serum iron/total iron binding capacity $\times 100 \%$.

Grouping

All patients were divided into 2 groups by the median of the ERI as follows: low ERI group (ERI $\leq 11.52$ IU/week $(\mathrm{g} / \mathrm{dL})^{-1} / \mathrm{kg}$ ) and high ERI group (ERI >11.52 IU/week $\left.(\mathrm{g} / \mathrm{dL})^{-1} / \mathrm{kg}\right)$.

\section{Statistical Analyses}

The SPSS 17.0 statistics package for Windows was used for statistical analysis. Normally distributed continuous variables were expressed as the mean $\pm \mathrm{SD}$, and Student $t$ tests were used for comparing the mean values of the data. Nonnormally distributed variables were shown as medians $\left(\mathrm{P}_{25}, \mathrm{P}_{75}\right)$, and comparisons between the 2 groups were analyzed by Mann-Whitney $U$ tests. Categorical variables were expressed as the number and percentage for each item, and chi-square analysis was used. The comparison among $>2$ groups was analyzed by one-way ANOVA (normally distributed continuous variables) or Kruskal-Wallis tests (nonnormally distributed variables). Multivariate logistic regression analysis was used for related factors of high ERI. $p<0.05$ was considered statistically significant.

\section{Results}

\section{Patient Characteristics}

A total of 307 patients were involved in this research and were analyzed. The mean age was $59.7 \pm 14.3$ years, $52.8 \%$ of the patients were male, and the mean dialysis vintage was 99 \pm 58 months. The primary diseases of the patients included chronic glomerulonephritis, 125 (40.7\%); diabetic renal disease, 59 (19.2\%); hypertensive-related nephropathy, 41 (13.4\%); chronic interstitial nephritis, 25 (8.1\%); and other diseases, 57 (18.6\%).

In the investigated patients, the serum magnesium level ranged from $0.76 \mathrm{mmol} / \mathrm{L}$ to $1.65 \mathrm{mmol} / \mathrm{L}$, and the mean serum magnesium level was $1.11 \pm 0.13 \mathrm{mmol} / \mathrm{L}$. We transformed the serum magnesium levels into a categorical variable that comprised 3 serum magnesium groups, which were defined according to the tertiles of the serum magnesium levels as follows: group $\mathrm{A}, \leq 33.3$ th percentile ( $\mathrm{Mg} \leq 1.05 \mathrm{mmol} / \mathrm{L}, n=105$ ); group $\mathrm{B}$, 33.4th-66.7th percentile $(1.05<\mathrm{Mg}<1.16 \mathrm{mmol} / \mathrm{L}, n=99)$; and group $\mathrm{C}, \geq 66.7$ th percentile $(\mathrm{Mg} \geq 1.16 \mathrm{mmol} / \mathrm{L}, n=103)$. The demographic and laboratory characteristics of the 3 groups are shown in Table 1.

\section{The Related Factors of EPO Responsiveness}

The ERI range of all patients was from (2.26 to 32.61) IU $/$ week (g/dL) ${ }^{-1} / \mathrm{kg}$, and the mean ERI was $(12.67 \pm 6.17) \mathrm{IU} /$ week $(\mathrm{g} / \mathrm{dL})^{-1} / \mathrm{kg}$. As shown in Table 2 , age, serum albumin, Hs-CRP, serum creatinine, iPTH, and magnesium groups were correlated with a high ERI according to the median ERI with univariate analysis. The index of transferrin saturation, serum ferritin, and the proportion of venous iron replacement therapy were similar in the 2 ERI groups $(p>0.05)$.

According to the multivariate logistic regression model using group $\mathrm{C}$ as the reference group (Table 3), the ERI grouping as the dependent variable, and age, serum albumin, Hs-CRP, serum creatinine, iPTH, and magnesium groups as covariates, which were significantly different according to the univariate analysis, the OR of group A was 2.57 (95\% CI 1.330-4.975, $p=0.005)$ and the OR of group B was 1.66 (95\% CI 0.878-3.140, $p=$ 0.119 ). 


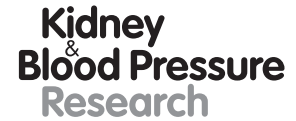

\begin{tabular}{l|l}
\hline Kidney Blood Press Res 2019;44:354-361 \\
\hline DOI: 10.1159/000500921 & $\begin{array}{l}\text { (c) 2019 The Author(s). Published by S. Karger AG, Basel } \\
\text { www.karger.com/kbr }\end{array}$ \\
\hline Yu et al.: Association between Serum Magnesium and EPO Responsiveness in
\end{tabular}

Yu et al.: Association between Serum Magnesium and EPO Responsiveness in Hemodialysis Patients: A Cross-Sectional Study

Table 1. Comparison of characteristics in the $3 \mathrm{Mg}$ groups

\begin{tabular}{|c|c|c|c|c|c|}
\hline \multirow[t]{2}{*}{ Characteristics } & \multicolumn{3}{|c|}{ Serum magnesium tertiles } & \multirow[t]{2}{*}{$F / \chi^{2}$} & \multirow[t]{2}{*}{$p$ value } \\
\hline & $\begin{array}{l}\mathrm{A}(\leq 1.05) \\
(n=105)\end{array}$ & $\begin{array}{l}\mathrm{B}(1.05<\mathrm{Mg}<1.16) \\
(n=99)\end{array}$ & $\begin{array}{l}C(\geq 1.16) \\
(n=103)\end{array}$ & & \\
\hline $\mathrm{Mg}, \mathrm{mmol} / \mathrm{L}$ & $0.98 \pm 0.06$ & $1.10 \pm 0.03$ & $1.25 \pm 0.08$ & - & - \\
\hline Age, years & $59.6 \pm 15.4$ & $59.9 \pm 12.9$ & $59.6 \pm 14.5$ & 0.022 & 0.978 \\
\hline Gender, male & $61(58.1)$ & $46(46.5)$ & $55(53.4)$ & 2.790 & 0.248 \\
\hline Body weight, kg & $62.33 \pm 12.60$ & $59.58 \pm 7.26$ & $61.19 \pm 9.97$ & 0.716 & 0.491 \\
\hline HD vintage, months & $97 \pm 61$ & $103 \pm 55$ & $98 \pm 54$ & 0.372 & 0.689 \\
\hline Serum albumin, g/L & $37.38 \pm 3.99$ & $38.52 \pm 3.70$ & $39.30 \pm 3.41$ & 7.085 & $0.001^{*}$ \\
\hline Hemoglobin, g/L & $109.73 \pm 14.41$ & $112.62 \pm 12.28$ & $120.67 \pm 12.02$ & 19.785 & $<0.001^{*}$ \\
\hline TSAT, $\%$ & $32.71 \pm 12.42$ & $31.28 \pm 10.06$ & $34.53 \pm 9.27$ & 1.769 & 0.173 \\
\hline sFerr, $\mu \mathrm{g} / \mathrm{L}$ & $342.07 \pm 197.89$ & $331.67 \pm 185.76$ & $353.05 \pm 189.62$ & 0.316 & 0.729 \\
\hline Hs-CRP, mmol/L & $5.25(2.11-9.44)$ & $3.26(1.00-6.42)$ & $3.02(1.27-6.43)$ & 11.166 & $0.004^{*}$ \\
\hline WBC, $\times 10^{9}$ & $6.27 \pm 1.93$ & $6.28 \pm 1.90$ & $6.29 \pm 1.87$ & 0.006 & 0.994 \\
\hline$n(\%)$ & $67.96 \pm 8.36$ & $67.07 \pm 9.12$ & $64.68 \pm 9.43$ & 3.442 & $0.033^{*}$ \\
\hline ALP, U/L & $118.55 \pm 53.55$ & $125.65 \pm 69.92$ & $110.49 \pm 44.61$ & 1.791 & 0.169 \\
\hline $\mathrm{P}, \mathrm{mmol} / \mathrm{L}$ & $1.77 \pm 0.53$ & $1.94 \pm 0.62$ & $1.86 \pm 0.52$ & 2.461 & 0.087 \\
\hline $\mathrm{cCa}, \mathrm{mg} / \mathrm{dL}$ & $8.74 \pm 0.93$ & $9.31 \pm 1.07$ & $9.24 \pm 0.89$ & 10.750 & $<0.001^{*}$ \\
\hline iPTH, ng/dL & 269.8 (149.7-433.9) & $282.95(209.8-549.1)$ & $271.3(175.6-424.3)$ & 4.235 & 0.120 \\
\hline
\end{tabular}

Data are presented as mean $\pm \mathrm{SD}$, median (interquartile range), or number (percentage).

* Significant difference among different serum magnesium groups, $p<0.05$.

Mg, magnesium; ERI, erythropoietin resistance index; CVD, cardiovascular disease; TSAT, transferrin saturation; sFerr, serum ferritin; Hs-CRP, high-sensitivity C-reactive protein; WBC, white blood count; N, neutrophilic granulocyte percentage; ALP, alkaline phosphatase; P, phosphorus; cCa, corrected serum calcium; iPTH, intact parathyroid hormone.

\section{Discussion}

In this study, we found that the serum magnesium level was significantly higher than the normal level in MHD patients, and none of the patients had hypomagnesemia, which were consistent with our previous research [8]. The regulation of serum magnesium relies mainly on the intake of intestinal and renal excretion [9]. In hemodialysis patients, where kidney function is abolished, serum magnesium levels are elevated and are higher than those in the healthy population. Because of the excretion of magnesium by regular hemodialysis (dialysis liquid magnesium is $0.5 \mathrm{mmol} / \mathrm{L}$ ), fatal hypermagnesemia is rare in hemodialysis patients [10].

Although EPO has been used in the clinic for many years and has greatly improved anemia, EPO hyporesponsiveness is still observed in some MHD patients. Several studies have demonstrated an association between EPO hyporesponsiveness and poor clinical outcomes, such as anemia, heart failure, and increased cardiovascular and all-cause mortality $[11,12]$. The ERI is a sensitive evaluation index of EPO responsiveness and can predict composite events (CVD, infection, hospitalization, or death) [13] and all-cause mortality in MHD patients $[14,15]$. Our study demonstrated that ERI values were from 2.26 to $32.61 \mathrm{IU} /$ week $(\mathrm{g} / \mathrm{dL})^{-1} / \mathrm{kg}$, and the mean ERI value was $(12.67 \pm 6.17) \mathrm{IU} /$ week $(\mathrm{g} / \mathrm{dL})^{-1} / \mathrm{kg}$. These results are consistent with data reported by other studies [16, 17].

The results of our study showed that a higher Hs-CRP and iPTH and/or a lower albumin level was associated with an increased risk of EPO hyporesponsiveness as established by the ERI, which were partly in line with the results reported by Mallick et al. [18]. Chronic inflammation produces cytokines, thus inhibiting erythropoiesis and shortening the lifespan of red 
Kidney
Blood Pressure

Research
Kidney Blood Press Res 2019;44:354-361

Yu et al.: Association between Serum Magnesium and EPO Responsiveness in Hemodialysis Patients: A Cross-Sectional Study

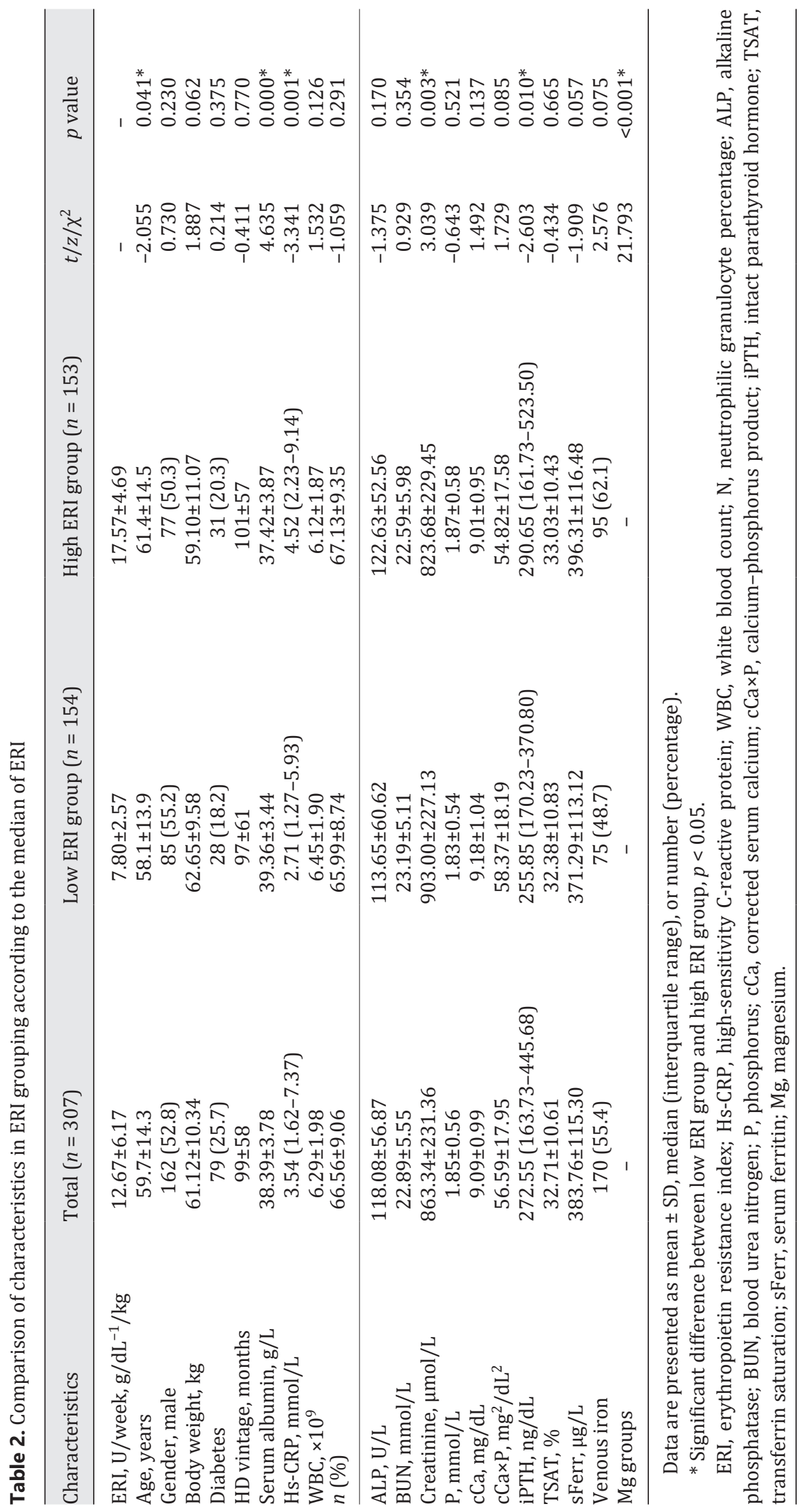


Kidney
Blood Pressure

Research

\begin{tabular}{l|l}
\hline Kidney Blood Press Res 2019;44:354-361 \\
\hline DOI: 10.1159/000500921 & $\begin{array}{l}\text { @ 2 2019 The Author(s). Published by S. Karger AG, Basel } \\
\text { www.karger.com/kbr }\end{array}$
\end{tabular}

Yu et al.: Association between Serum Magnesium and EPO Responsiveness in Hemodialysis Patients: A Cross-Sectional Study

Table 3. Binary classification logistic multivariate regression model of ERI

\begin{tabular}{|c|c|c|c|c|c|c|}
\hline Independent variable & $\begin{array}{l}\text { Regression } \\
\text { coefficient }\end{array}$ & SE & Wald & OR & $95 \% \mathrm{CI}$ & $p$ value \\
\hline Age, 1 year & 0.009 & 0.012 & 0.551 & 0.009 & $0.986-1.032$ & 0.458 \\
\hline $\mathrm{Hs}-\mathrm{CRP}, 1 \mathrm{mmol} / \mathrm{L}$ & 0.100 & 0.037 & 7.268 & 1.106 & $1.028-1.189$ & $0.007^{*}$ \\
\hline $\mathrm{iPTH}, 1 \mathrm{ng} / \mathrm{dL}$ & 0.002 & 0.001 & 10.763 & 1.002 & $1.001-1.003$ & $0.001^{*}$ \\
\hline $\mathrm{Alb}, 1 \mathrm{~g} / \mathrm{L}$ & -0.119 & 0.039 & 9.479 & 0.888 & $0.823-0.958$ & $0.002^{*}$ \\
\hline Creatinine, 1 umol/L & -0.001 & 0.001 & 2.078 & 0.999 & $0.998-1.000$ & 0.149 \\
\hline Mg groups $^{\mathrm{a}}$ & & & & & & $0.019^{*}$ \\
\hline Group A & 0.945 & 0.337 & 7.878 & 2.572 & $1.330-4.975$ & $0.005^{*}$ \\
\hline Group B & 0.507 & 0.325 & 2.434 & 1.661 & $0.878-3.140$ & 0.119 \\
\hline
\end{tabular}

${ }^{\text {a }}$ Group C was used as the reference group.

* Significant association, $p<0.05$.

ERI, erythropoietin resistance index; Hs-CRP, high-sensitivity C-reactive protein; iPTH, intact parathyroid hormone; Alb, serum albumin; Mg, magnesium.

blood cells $[19,20]$. In patients with secondary hyperparathyroidism, parathyroid hormone can reduce the synthesis of endogenous EPO, inhibit the maturation of erythrocyte precursors, and shorten the erythrocyte lifespan by increasing the osmotic fragility of erythrocytes $[21,22]$.

Zhan et al. [23] demonstrated that there was an inverse association between serum magnesium and anemia in a large cohort of Chinese adults. However, similar studies in MHD patients are rare [8]. This study found that the risk of EPO hyporesponsiveness was 2.57 times greater in the lowest magnesium group compared with that in the highest magnesium group. However, the mechanism of the effect of serum magnesium on EPO responsiveness is unclear. Several lines of evidence indicate that serum magnesium may play a role in various ways. First, magnesium is the second most abundant intracellular cation after potassium and is a co-factor in $>300$ enzymatic reactions involving energy metabolism, protein and nucleic acid synthesis, and the balance of membrane potential. Therefore, EPO responsiveness was improved by affecting the energy metabolism of erythrocytes and the synthesis of hemoglobin. Second, oxidative stress could induce EPO hyporesponsiveness in anemia during endstage renal disease [24]. Animal studies showed that magnesium deficiency led to the generation of reactive oxygen species by enhancing the recruitment of phagocytic cells [25]. Magnesium deficiency may increase intracellular $\mathrm{Ca}^{2+}$ by activating the L-type calcium channel [26] and enhance the activation of the N-methyl-D-aspartate receptor [27]. Increased intracellular $\mathrm{Ca}^{2+}$, which is considered a signal to initiate the inflammatory process, induces the production of pro-inflammatory cytokines, such as tumor necrosis factor- $\alpha$ and interleukin-1 $[28,29]$. Third, low magnesium levels rendered endothelial cells more susceptible to the detrimental effects of lipopolysaccharide. Lee et al. [30] demonstrated that higher serum magnesium levels may be associated with better endothelial function in MHD patients. Fourth, higher magnesium intake or serum magnesium improved insulin sensitivity [31-33], which was associated with EPO responsiveness in MHD patients [34]. Finally, magnesium supplementation significantly increased serum albumin in chronic kidney disease patients [33]. Magnesium improved EPO responsiveness, which may be mediated partly by increasing serum albumin.

This study had several important limitations. First, as a single-center cross-sectional study, our data may not be representative of MHD patients in other countries. In addition, it was simple that the grouping according to the median ERI represented the degree of EPO responsiveness. Finally, the serum magnesium level represented only a single measurement, 
whereas the level may change over time. We will clarify whether magnesium supplementation is beneficial for improving the EPO responsiveness in future studies.

\section{Conclusion}

We demonstrated that serum magnesium levels were higher than normal levels in MHD patients. Hs-CRP, iPTH, serum albumin, and magnesium levels were factors correlated with EPO responsiveness. A high serum magnesium level was correlated with good EPO responsiveness. Further studies should elucidate whether magnesium supplementation, including dietary supplements and treatment with magnesium-based phosphate binders or increasing magnesium concentration in dialysate fluid, could have any potential benefits for improving EPO responsiveness in hemodialysis patients in an iron-sufficient state.

\section{Acknowledgment}

No specific financial support was obtained for this article.

\section{Disclosure Statement}

The authors have no conflicts of interest to declare.

\section{Author Contributions}

L.Y. and H.L.: conceived and designed the research. L.Y., J.S., and X.L.: collected the data. L.Y. and Y.Z.: analyzed the data. L.Y., J.S., X.L., Y.Z., H.L., and S.W.: wrote the paper.

\section{References}

1 Vaziri ND, Zhou XJ. Potential mechanisms of adverse outcomes in trials of anemia correction with erythropoietin in chronic kidney disease. Nephrol Dial Transplant. 2009 Apr;24(4):1082-8.

2 Lau JH, Gangji AS, Rabbat CG, Brimble KS. Impact of haemoglobin and erythropoietin dose changes on mortality: a secondary analysis of results from a randomized anaemia management trial. Nephrol Dial Transplant. 2010 Dec;25(12):4002-9.

3 Ogawa T, Shimizu H, Kyono A, Sato M, Yamashita T, Otsuka K, et al. Relationship between responsiveness to erythropoiesis-stimulating agent and long-term outcomes in chronic hemodialysis patients: a single-center cohort study. Int Urol Nephrol. 2014 Jan;46(1):151-9.

4 Bellinghieri G, Condemi CG, Saitta S, Trifirò G, Gangemi S, Savica V, et al. Erythropoiesis-stimulating agents: dose and mortality risk. J Ren Nutr. 2015 Mar;25(2):164-8.

5 Kanbay M, Perazella MA, Kasapoglu B, Koroglu M, Covic A. Erythropoiesis stimulatory agent- resistant anemia in dialysis patients: review of causes and management. Blood Purif. 2010;29(1):1-12.

6 Sakaguchi Y, Fujii N, Shoji T, Hayashi T, Rakugi H, Isaka Y. Hypomagnesemia is a significant predictor of cardiovascular and non-cardiovascular mortality in patients undergoing hemodialysis. Kidney Int. 2014 Jan;85(1): 174-81.

7 Sakaguchi Y, Fujii N, Shoji T, Hayashi T, Rakugi H, Iseki K, et al.; Committee of Renal Data Registry of the Japanese Society for Dialysis Therapy. Magnesium modifies the cardiovascular mortality risk associated with hyperphosphatemia in patients undergoing hemodialysis: a cohort study. PLoS One. 2014 Dec;9(12):e116273.

8 Yu L, Li H, Wang SX. Serum Magnesium and Mortality in Maintenance Hemodialysis Patients. Blood Purif. 2017;43(1-3):31-6.

9 Blaine J, Chonchol M, Levi M. Renal control of calcium, phosphate, and magnesium homeostasis. Clin J Am Soc Nephrol. 2015 Jul;10(7):1257-72.

10 Yoon HE, Kim YW, Ha KS, Sim EH, Go SW, Shin SJ. Hypermagnesemia accompanied with colonic perforation in a hemodialysis patient. Yonsei Med J. 2013 May;54(3):797-800. 


\section{Kidney \\ Blood Pressure \\ Research}

\begin{tabular}{l|l}
\hline Kidney Blood Press Res 2019;44:354-361 \\
\hline DOI: 10.1159/000500921 & $\begin{array}{l}\text { @ 2019 The Author(s). Published by S. Karger AG, Basel } \\
\text { www.karger.com/kbr }\end{array}$ \\
\hline
\end{tabular}

Yu et al.: Association between Serum Magnesium and EPO Responsiveness in Hemodialysis Patients: A Cross-Sectional Study

11 Szczech LA, Barnhart HX, Inrig JK, Reddan DN, Sapp S, Califf RM, et al. Secondary analysis of the CHOIR trial epoetin-alpha dose and achieved hemoglobin outcomes. Kidney Int. 2008 Sep;74(6):791-8.

12 Kilpatrick RD, Critchlow CW, Fishbane S, Besarab A, Stehman-Breen C, Krishnan M, et al. Greater epoetin alfa responsiveness is associated with improved survival in hemodialysis patients. Clin J Am Soc Nephrol. 2008 Jul;3(4):1077-83.

13 Kuragano T, Kitamura K, Matsumura O, Matsuda A, Hara T, Kiyomoto H, et al. ESA Hyporesponsiveness Is Associated with Adverse Events in Maintenance Hemodialysis (MHD) Patients, But Not with Iron Storage. PLoS One. 2016 Mar;11(3):e0147328.

14 Eriguchi R, Taniguchi M, Ninomiya T, Hirakata H, Fujimi S, Tsuruya K, et al. Hyporesponsiveness to erythropoiesis-stimulating agent as a prognostic factor in Japanese hemodialysis patients: the Q-Cohort study. J Nephrol. 2015 Apr;28(2):217-25.

15 Okazaki M, Komatsu M, Kawaguchi H, Tsuchiya K, Nitta K. Erythropoietin resistance index and the all-cause mortality of chronic hemodialysis patients. Blood Purif. 2014;37(2):106-12.

16 López-Gómez JM, Portolés JM, Aljama P. Factors that condition the response to erythropoietin in patients on hemodialysis and their relation to mortality. Kidney Int Suppl. 2008 Dec;74(111):S75-81.

17 Chang JH, Jung JY, Lee HH, Chung W, Joo KW, Kim S. Serum resistin as a novel marker of erythropoietin resistance in nondiabetic patients on hemodialysis. Tohoku J Exp Med. 2011 Aug;224(4):281-5.

18 Mallick S, Rafiroiu A, Kanthety R, Iqbal S, Malik R, Rahman M. Factors predicting erythropoietin resistance among maintenance hemodialysis patients. Blood Purif. 2012;33(4):238-44.

19 Kimachi M, Fukuma S, Yamazaki S, Yamamoto Y, Akizawa T, Akiba T, et al. Minor Elevation in C-Reactive Protein Levels Predicts Incidence of Erythropoiesis-Stimulating Agent Hyporesponsiveness among Hemodialysis Patients. Nephron. 2015;131(2):123-30.

20 Inrig JK, Bryskin SK, Patel UD, Arcasoy M, Szczech LA. Association between high-dose erythropoiesis-stimulating agents, inflammatory biomarkers, and soluble erythropoietin receptors. BMC Nephrol. 2011 Dec;12(1): 67.

21 Romero JR, Youte R, Brown EM, Pollak MR, Goltzman D, Karaplis A, et al. Parathyroid hormone ablation alters erythrocyte parameters that are rescued by calcium-sensing receptor gene deletion. Eur J Haematol. 2013 Jul; 91(1):37-45.

22 Khoury N, Chang J, Gru AA, Whyte MP. Resorptive hypercalcemia in post-essential thrombocythemia myelofibrosis: treatment with denosumab. J Clin Endocrinol Metab. 2012 Sep;97(9):3051-5.

23 Zhan Y, Chen R, Zheng W, Guo C, Lu L, Ji X, et al. Association between serum magnesium and anemia: china health and nutrition survey. Biol Trace Elem Res. 2014 Jun;159(1-3):39-45.

24 Khalil SK, Amer HA, El Behairy AM, Warda M. Oxidative stress during erythropoietin hyporesponsiveness anemia at end stage renal disease: molecular and biochemical studies. J Adv Res. 2016 May;7(3):348-58.

25 Libako P, Nowacki W, Rock E, Rayssiguier Y, Mazur A. Phagocyte priming by low magnesium status: input to the enhanced inflammatory and oxidative stress responses. Magnes Res. 2010 Mar;23(1):1-4.

26 Lin CY, Tsai PS, Hung YC, Huang CJ. L-type calcium channels are involved in mediating the anti-inflammatory effects of magnesium sulphate. Br J Anaesth. 2010 Jan;104(1):44-51.

27 Weglicki WB. Hypomagnesemia and inflammation: clinical and basic aspects. Annu Rev Nutr. 2012 Aug;32(1): $55-71$.

28 Sugimoto J, Romani AM, Valentin-Torres AM, Luciano AA, Ramirez Kitchen CM, Funderburg N, et al. Magnesium decreases inflammatory cytokine production: a novel innate immunomodulatory mechanism. J Immunol. 2012 Jun;188(12):6338-46.

29 Gao F, Ding B, Zhou L, Gao X, Guo H, Xu H. Magnesium sulfate provides neuroprotection in lipopolysaccharideactivated primary microglia by inhibiting NF-кB pathway. J Surg Res. 2013 Oct;184(2):944-50.

30 Lee S, Ryu JH, Kim SJ, Ryu DR, Kang DH, Choi KB. The Relationship between Magnesium and Endothelial Function in End-Stage Renal Disease Patients on Hemodialysis. Yonsei Med J. 2016 Nov;57(6):1446-53.

31 Moctezuma-Velázquez C, Gómez-Sámano MÁ, Cajas-Sánchez MB, Reyes-Molina DL, Galindo-Guzmán M, MezaArana CE, et al. High Dietary Magnesium Intake is Significantly and Independently Associated with Higher Insulin Sensitivity in a Mexican-Mestizo Population: A Brief Cross-Sectional Report. Rev Invest Clin. 2017 Jan-Feb;69(1):40-6.

32 Shamnani G, Bhartiy SS, Jiwane R, Gupta V, Verma N, Verma D. Correlation of serum magnesium with insulin resistance in North Indian adult population. Curr Diabetes Rev. 2018, Epub ahead of print.

33 Toprak O, Kurt H, Sarı Y, Sarkıs C, Us H, Kırık A. Magnesium Replacement Improves the Metabolic Profile in Obese and Pre-Diabetic Patients with Mild-to-Moderate Chronic Kidney Disease: A 3-Month, Randomised, Double-Blind, Placebo-Controlled Study. Kidney Blood Press Res. 2017;42(1):33-42.

34 Abe M, Okada K, Soma M, Matsumoto K. Relationship between insulin resistance and erythropoietin responsiveness in hemodialysis patients. Clin Nephrol. 2011 Jan;75(1):49-58. 